\title{
Investigatory Study of Long Term Doses of Costus afer, Snail Slime, and Their Combination with a Standard Pharmaceutical Drug on Blood Glucose Level of Alloxan Induced Swiss Albino Rat
}

\author{
Matthew Onyema Agu'1*, Barminas Jeff Tsware², A. Osemeahon Sunday33, Jude Chinedu Onwuka4, \\ Hotton Joseph Anthony5
}

${ }^{1}$ Department of Science Laboratory Technology, Federal Polytechnic Bali, Jalingo, Nigeria

${ }^{2}$ National Research Institute for Chemical Technology, Zaria, Nigeria

${ }^{3}$ Department of Chemistry, Modibbo Adama University of Technology, Yola, Nigeria

${ }^{4}$ Department of Chemistry, Federal University, Lafia, Nigeria

${ }^{5}$ NAFDAC, Office Complex, Chemical Evaluation and Research Directorate, Lagos, Nigeria

Email: *mataguonyema@gmail.com

How to cite this paper: Agu, M.O., Tsware, B.J., Sunday, A.O., Onwuka, J.C. and Anthony, H.J. (2018) Investigatory Study of Long Term Doses of Costus afer, Snail Slime, and Their Combination with a Standard Pharmaceutical Drug on Blood Glucose Level of Alloxan Induced Swiss Albino Rat. Open Journal of Medicinal Chemistry, 8, 1-14.

https://doi.org/10.4236/ojmc.2018.81001

Received: February 3, 2018

Accepted: March 27, 2018

Published: March 30, 2018

Copyright $\odot 2018$ by authors and Scientific Research Publishing Inc. This work is licensed under the Creative Commons Attribution International License (CC BY 4.0).

http://creativecommons.org/licenses/by/4.0/

(c) (i) Open Access

\begin{abstract}
The Plant, Costus afer Ker Gawl. belongs to the family of Costaceae and has various uses where they exist. Their use in folk medicine and phytomedicine is in the treatment and management of variety of human ailment, like diabetes mellitus, abdominal problems etc. The search for new antidiabetic therapies has become increasingly urgent due to the development of adverse effects and resistance by the chemically synthesized drugs on one hand and effectiveness with low cost of the plant materials on the other hand. The investigations carried out is to determine the long term effects of Costus afer leaf methanol extract, snail slime and the combined Costus afer and snail slime extracts on blood glucose levels of alloxan induced diabetic Swiss albino rats treated orally for 21 days on graded dose of $(100 \mathrm{mg} / \mathrm{kg}$ and $300 \mathrm{mg} / \mathrm{kg})$. From the determination, the snail slime showed positive effect on blood glucose lowering level but less effective when compared with similar dose of the Costus afer leaf methanol extract. The investigation indicated that there was $103 \mathrm{mg} / \mathrm{dL}$ and $87 \mathrm{mg} / \mathrm{dL}$ blood glucose reduction for the low dose of Costus afer and Snail slime respectively while the standard hypoglycemic drug (Glibenclamide, 5 $\mathrm{mg} / \mathrm{kg}$ ) used for comparison yielded a blood glucose level reduction of 103 $\mathrm{mg} / \mathrm{dL}$. Similarly, the high dose used in the study gave a blood glucose reduction of $99 \mathrm{mg} / \mathrm{dL}$ and $95 \mathrm{mg} / \mathrm{dL}$ for Costus afer leaf methanol extract and Snail
\end{abstract}


slime respectively. The results obtained when alloxan induced rats was treated with $C$. afer leaf methanol extract, Snail slime extract, and combined $C$. afer and snail slime extracts was analysed using Statistix 8.0 American version. The result showed a dose dependent fashion and the difference obtained from the compared results was statistically significant at $\mathrm{p}<0.05$. This result supports the views of other researchers that some herbal anti-diabetic remedies which reduce blood glucose levels were similar to those of synthetic oral hypoglycemic drugs like metformin and sulfonylurea etc [1]. Still to that, medicinal and pharmacological activities of medicinal plants are often attributed to the presence of the so called secondary plant metabolites. Hence this regenerative capacity of snail slime and the fact that diabetes is characterized by damage of the pancreatic beta cells, may give credit to the hypoglycaemic effect observed in Costus afer methanol leaf extract and snail slime for possible drug formulation for anti-diabetic remedy. Our findings may approve snail slime which is insoluble in both acid and alkaline medium, to act as a carrier of chemical and biological nanoparticles for medical and pharmaceutical use.

\section{Keywords}

Nanoparticles, Combined Costus afer and Snail Slime Extract, Hypoglycaemic, Glibenclamide, Phytomedicine, Snail Slime, Costus afer, Antidiabetic

\section{Introduction}

In recent time, the leaf of the plant Costus afer Ker Gawl. (Costaceae family) is traditionally well known for its anti-hyperglycaemic and insulin secretory activity apart from a number of other plant species known to possess diabetic control properties. Costus afer is shown in Figure 1. The plant is commonly called Ginger lily or Bush cane in English. The Igbo people call it "Okpete" or "Okpoto", were as the Hausa of Northern Nigeria and Yoruba of Western Nigeria refer it as "Kakizawa" and "Tete-egun" [2], [3] respectively.

In Nigeria, Snail is called different names with respect to the geographical location as recorded in [4]. In Northern Nigeria, the Hausa tribe call it Dodon Kodi while in the Eastern Nigeria, that is, the Igbo community and Yoruba in the Western Nigeria call it Ejula and Igbi respectively. As it is known, Snail uses its slime to regenerate its shell and skin when broken and damaged. Looking at the fact that diabetes is characterized by damage of the pancreatic beta cells, and snail is capable of using its slime to regenerate its broken shell lead to this investigation of the activity of $C$. afer leaf extract, snail slime and their combination for possible anti-diabetic remedy through regeneration of the pancreatic beta cells.

Since time in memorial, people have used herbal medicine or phytomedicine for the purpose of treatment, control and management of varieties of ailments [5] [6] [7]. 


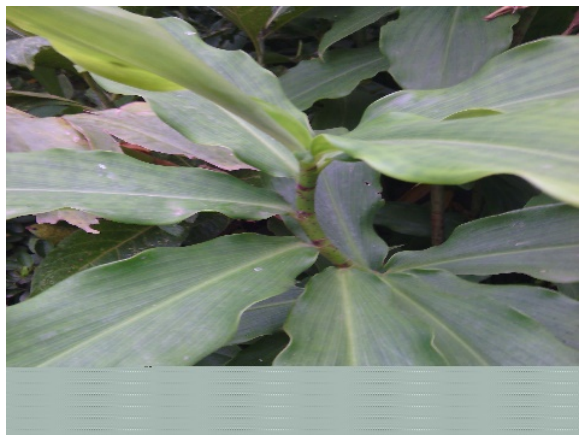

(a)

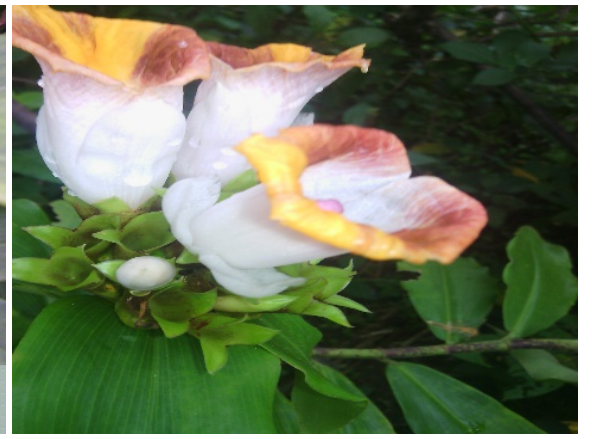

(b)

Figure 1. (a) The leaf of Costus afer, (b) Flower of Costus afer.

Back home in Nigeria and Africa, much is not known in this developmental trend of prehistoric herbal records of ancient African traditional medicine systems because African tradition systems of medicines are poorly recorded up till date [8] [9].

However, it was discovered and established through consultations with African traditional practioneers and testing that African medicine has therapeutic potentials [10]. The following plants Acacia senegal (Gum Arabic), Agathosma betulina (Buchu), Aloe ferox (Cape Aloes), Aloe vera (North African Origin), Artemisia afra (African wormwood), etc. has gone through such repeated testing [10].

Based on the discovered therapeutic potentials prior to, during and after the nineteenth century, plant medicines were administered mostly in their crude forms as herbal teas, alcoholic extracts, decoctions (boiled extract of roots or bark), syrup (extracts of herbs made with syrup or honey) or applied externally as ointments in form of balms and essential oils [11] [12].

During the late nineteenth and early twentieth centuries, scientists began isolating, purifying and identifying active ingredients from medicinal plant extracts [7] [12] [13]. This developmental changes led to the discovery of some of the most important drugs that are still widely used today in modern medicine [14], [15] [16]. For example, morphine isolated from opium poppy (Papaver somniferum) is a powerful pain reliever and narcortic, quinine isolated from Cinchona plant species is an effective anti-malarial drug

From the report of World Health Organization (WHO) [17], $60 \%$ of the world's population depends on traditional medicine, whereas $80 \%$ of the population in developing countries depend almost entirely on traditional medicine practices, for their primary health care needs [18] [19]. Although there is a decrease in the direct use of plant extracts in developed countries in the nineteenth and early twentieth centuries still medicinal plants play a role in health care system of many parts of the world [6] [20]. The long tradition of herbal medicine is still prominent to the present day Nigeria, India, South America, China and many other countries in Africa [6] [19] [20]. To testify for the existence and use of medicinal plants as reported by [6] [20], it is sold alongside other wares in 
many village marketplaces of these countries. In Nigeria and other developing countries that practices the use of medicinal herbs, practioneers of herbal medicine often undergo a rigorous and extended training to learn the names, uses and preparation of native plants for many years [8].

The aim of the study is to investigate the anti-diabetic potentials of bioactive crude Costus afer methanol leaf extract, giant African land snail slime and their combination through the following objectives:

1) To investigate the acute in vivo effect of active crude Costus afer methanol leaf extract, snail slime and their combination on fasting blood glucose levels of normal and alloxan-induced diabetic white Albino rats.

2) To investigate the long term (21 days) in vivo effects of active crude Costus afer extract, snail slime, their combination and Glibenclamide tablets (commercial oral anti-hypoglycemic drug) on fasting blood glucose and body weight in normal and alloxan-induced diabetic white Albino rats.

\section{Materials and Methods}

\subsection{Collection and Preparation of Plant and Animal Materials}

Costus afer Ker Gawl was also collected from Duruogbuji-Umuewi village in Njaba L.G.A. of Imo State.

The method of [4] with modification was used for plant preparation whereby the plant leaves were washed, air dried on the laboratory tables and pulverized using Corona hand grinder. To obtain the methanol extracts, $200 \mathrm{~g}$ of plant materials was soaked in $1000 \mathrm{ml}$ of methanol using cold maceration technique. In this process, the whole or coarsely powdered crude drug was placed in a stoppered container with the solvent and allowed to stand at room temperature for a period of 2 days (i.e. $48 \mathrm{~h}$ ) with frequent agitation. The mixture then was strained, the marc (the damp solid material) was pressed, and the combined liquids were clarified by filtration. As the residue was removed by filtration, the filtrate was concentrated (distilled, evaporated and vacuum dried) under reduced pressure by a rotary evaporator at $40^{\circ} \mathrm{C}$.

\subsection{Purchase, Preparation and Extraction of Snail Slime from Giant African Land Snail}

The giant African Land Snails was purchased from Afor Awo-Omamma market in Oru-East Local Government Area of Imo State.

The method of [21] with modification was employed for the preparation and extraction of snail slime from the Giant African Land Snail. Giant African Land Snail and snail slime are shown in Figure 2. The Giant African Land Snails (Achachatina marginata) were washed with clean water to remove dirt and dust particles on the shells. The shells were knocked open at the apex. The inner content (i.e. fleshy body) of the snails was separated from the shells by a mechanical means involving the use of a spirally coiled rod inserted to remove the fleshy body. The mucus layer (slime) was gently scrapped off from the fleshy parts, 


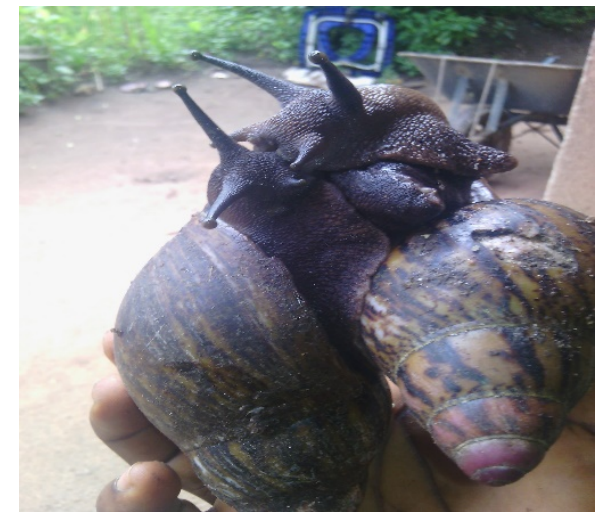

(a)

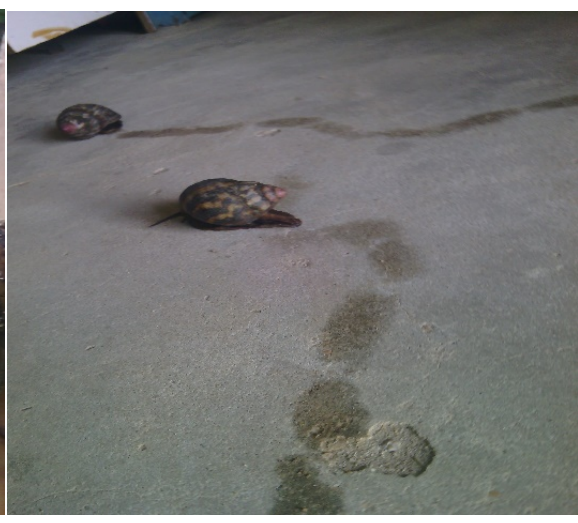

(b)

Figure 2. (a) Giant African Land Snail; (b) Trail of Snail (snail slime).

pooled together in a container and precipitated with chilled acetone. The precipitates was freeze dried $\left(-4^{\circ} \mathrm{C}\right)$ to obtain greyish-brown flakes of the snail slime extract, which was then pulverized into fine powder bottled and stored in a refrigerator for further studies.

\subsection{Formulation (Combination of $C$. afer and Snail Slime Extract) for Anti-Diabetic Drug}

The method of [22] was employed for the drug formulation with slight modification. Equal ratio (1:1) of Costus afer and Snail Slime extracts was properly mixed using a magnetic stirrer. The drug formulation was achieved by allowing the Costus afer extract in the beaker stirred at $3000 \mathrm{rpm}$ for $10 \mathrm{~min}$ by the magnetic stirrer before the drop wise addition of the Snail Slime onto the Costus afer extract using $10 \mathrm{ml}$ syringe continuously. The mixture was further allowed to stir for 30 minutes for proper homogenization. The content was dried in an oven at $40^{\circ} \mathrm{C}$ overnight (12 h). The resulting formulation (drug) was dissolved in double distilled water and administered to the animals orally.

\subsection{Procurement and Laboratory Maintenance of the Animal Model (Rats) Used for the Study}

Albino rats of equal but different sexes with body weight ranging from (140 $220 \mathrm{~g}$ ) were obtained from University of Jos, Nigeria, and used for the study. The animals were maintained in a laboratory temperature between $28^{\circ} \mathrm{C}$ to $32^{\circ} \mathrm{C}$. The animals were fed standard rat pellets feed and filtered water ad libitum. The animals were kept in individual cages in an environmentally controlled room with a $12 \mathrm{~h}$ light/12h dark cycle. Animals described as fasted were deprived of food for $24 \mathrm{~h}$ but allowed free access to water. The animals were used according to the institutions' approved animal ethics guidelines for research and analysis.

\subsection{Experimental Grouping of Animal}

The experimental rats were divided into nine (9) groups of five (5) animals in each group. The rats that showed diabetic and healthy were randomly selected 
and distributed into 9 groups of 5 animals each. Animals in the different groups received either distilled water, left untreated or graded doses $(100 \mathrm{mg} / \mathrm{kg}$ and 300 $\mathrm{mg} / \mathrm{kg}$ ) of the extracts and standard hypoglycaemic drug (Glibenclamide). The extract was administered for a period of 21 days ( 3 weeks). Body weights of the animals were recorded every week. The animal grouping is as follows:

Group 1: Diabetic control (Untreated).

Group 2: Normal control (Distilled water).

Group 3: Snail Slime (SSE); $100 \mathrm{mg} / \mathrm{kg}$ b.w.

Group 4: Snail Slime (SSE); 300 mg/kg b.w.

Group 5: Costus afer Leaf Extract (CaLE); $100 \mathrm{mg} / \mathrm{kg}$ b.w.

Group 6: Costus afer Leaf Extract (CaLE); $300 \mathrm{mg} / \mathrm{kg}$ b.w.

Group 7: The combined extracts (CaLE/SSE); $100 \mathrm{mg} / \mathrm{kg}$ b.w.

Group 8: The combined extracts (CaLE/SSE) $300 \mathrm{mg} / \mathrm{kg}$ b.w.

Group 9: Glibenclamide (Standard Pharmaceutical drug); $5 \mathrm{mg} / \mathrm{kg}$.

CaLE $=$ Costus afer Leaf Extract, SSE $=$ Snail Slime Extract, $b / w=$ Body weight.

\subsection{Induction of Experimental Diabetes}

Diabetes Mellitus (DM) type 1 was induced in groups of 25 Albino rats by intraperitoneal administration of alloxan monohydrate ( $150 \mathrm{mg} / \mathrm{kg}$ body weight) after an overnight fast (with access to only water) of $12 \mathrm{~h}$ to make them more susceptible to developing diabetes [23] [24]. After $24 \mathrm{~h}$, rats with diabetes mellitus was indicated by glycosuria and hyperglycemia with blood glucose range of 180 to $200 \mathrm{mg} / \mathrm{dL}$ body weight and bearing in mind to record the initial blood glucose level of all experimental rats at the start of the experiment. The animals were maintained in a diabetic state over a period of 21 days ( 3 weeks). Fasting blood glucose level was measured using glucometer (ONETOUCH-Ultra2 Blood Glucose Monitoring System).

\subsection{Animal Treatment with Extract (Costus afer Plant and Snail Slime)}

The plant and snail slime extracts were dissolved in distilled water according to the recommended graded doses of $100 \mathrm{mg} / \mathrm{kg}$ and $300 \mathrm{mg} / \mathrm{kg}$ of body weight for the experiment and given to the animals orally using an oral feeding needle (gavage). The blood glucose level was immediately monitored by One Touch Glucometer which is expressed in $\mathrm{mg} / \mathrm{dL}$ of blood and the body weight determined at the same time. The blood sample were collected at on the following days (Day 0, Day 4, Day 7, Day 14 and Day 21) for all the nine groups of 5 animals each, by tail bleeding.

\subsection{Induction of Experimental Diabetes}

The fasting blood glucose levels test was performed in experimental and control rats in accordance to the method described by [4] [23] [25] with some modifications. This study was carried out using both male and female albino rats of body 
weight from 140 - $220 \mathrm{~g}$. They were grouped and kept with not more than 5 animals per cage under similar laboratory conditions. The male rats that has fasted for $18 \mathrm{~h}$ was induced with $100 \mathrm{mg} / \mathrm{kg}$ of freshly prepared alloxan monohydrate intraperitoneally while the female rat of similar fasting hours was induced with diabetes after intraperitoneally (i.p) administration of $90 \mathrm{mg} / \mathrm{kg}$ of alloxan monohydrate. After three days the blood samples of the rats were collected and tested (analyzed) for blood glucose level. All the rats that showed blood glucose level above $180-245 \mathrm{mg} / \mathrm{dL}$ were considered and selected as diabetic and used for further analysis. The entire fasting blood glucose test was carried out using Glucometer (ONETOUCH-Ultra2 model).

\subsection{Determination of the Volume of Extract to Be Administered to the Animals}

The volume of Plant and Snail Slime extracts administered to the animals was calculated using the method adopted by [26]:

$$
\text { Volume of the extract }(\mathrm{mL})=\frac{\text { Weight of rat }(\mathrm{kg}) \times \text { Dose rate }(\mathrm{mg} / \mathrm{kg})}{\text { Extract concentration }(\mathrm{mg} / \mathrm{mL})}
$$

\subsection{Long Term Anti-Diabetic effects of $C$. afer Leaf extract, Snail Slime, Combined $C$. afer and Snail Slime Extract and Standard Pharmaceutical Drug on Alloxan Induced Rats}

Alloxan-induced and normal experimental rats were given a daily graded dose of $100 \mathrm{mg} / \mathrm{kg}$ body weight and $300 \mathrm{mg} / \mathrm{kg}$ body weight of $C$. afer leaf extract, snail slime, combined $C$. afer and Snail slime extract and standard pharmaceutical drug orally for three weeks. Control animals receive only water during the same period. Fasting blood glucose levels were determined by means of ONETOUCH-Ultra2 Glucometer (a diabetic fasting blood glucose monitoring system with blood glucose test strips) on day 0 , day 4 , day 7 , day 14 , and day 21 after initiation of treatment. Body weights of all groups of rats were measured on the same days that blood glucose levels were accessed.

\section{Results and Discussion}

The 21 Days Effect of $C$. afer Leaf Extract, Snail Slime and Combined C. afer and Snail Slime Extract With Standard Synthetic Hypoglycaemic Drug on Fasting Blood Glucose Levels of Alloxan Induced Rats

Table 1 and Table 2 shows the summary of the result of the acute effect of low dose $(100 \mathrm{mg} / \mathrm{kg})$ and high dose $(300 \mathrm{mg} / \mathrm{kg})$ C. afer leaf extract, Snail Slime and combined $C$. afer and snail slime extract on blood glucose levels after oral daily administration for 21 days. The result obtained for the mean and standard deviation on five treated animal model per group (Mean $\pm S_{D}$; and $n=5$ ) were shown on Table 1 and Table 2.

From the investigation shown on Table 1, there was an indication of significant reduction of the fasting blood glucose level from an average of $228 \mathrm{mg} / \mathrm{dL}$ 
Table 1. Shows the result of the effect of low dose (100 mg/kg) C. afer, Snail Slime, and, combined (C. afer and snail slime) extract on blood glucose level of alloxan induced Albino rats.

\begin{tabular}{|c|c|c|c|c|c|c|c|}
\hline \multirow{2}{*}{ Group } & \multirow{2}{*}{$\begin{array}{c}\text { Dose } \\
(\mathrm{mg} / \mathrm{kg})\end{array}$} & \multirow{2}{*}{$\begin{array}{l}\text { Differences in } \\
\text { Body weight }(\mathrm{g})\end{array}$} & \multicolumn{5}{|c|}{ Blood glucose levels (mg/dL) } \\
\hline & & & Day 0 & Day 4 & Day 7 & Day 14 & Day 21 \\
\hline $\begin{array}{l}\text { Normal } \\
\text { Control }\end{array}$ & & +0.3 & $110 \pm 8$ & $109 \pm 6$ & $111 \pm 3$ & $110 \pm 6$ & $114 \pm 7$ \\
\hline CaLE & 100 & -0.4 & $228 \pm 12$ & $212 \pm 7$ & $185 \pm 11$ & $142 \pm 6$ & $125 \pm 7$ \\
\hline SSE & 100 & -0.3 & $220 \pm 11$ & $204 \pm 11$ & $183 \pm 13$ & $160 \pm 7$ & $133 \pm 2$ \\
\hline CaLESSE & 100 & -0.4 & $220 \pm 7$ & $202 \pm 3$ & $180 \pm 4$ & $145 \pm 4$ & $124 \pm 4$ \\
\hline GC & 5 & -0.4 & $239 \pm 13$ & $190 \pm 123$ & $145 \pm 9$ & $123 \pm 5$ & $103 \pm 2$ \\
\hline
\end{tabular}

$\mathrm{S}_{\mathrm{D}}=$ standard deviation $;$ Mean and $\mathrm{n}=$ number of the animals per group; - = reduction in body weight, $+=$ increase in body weight, CaLe $=$ Costus afer Leaf Extract, SSE $=$ Snail Slime Extract, GC $=$ Glibenclamide.

Table 2. Shows the result of the effect of high dose $(300 \mathrm{mg} / \mathrm{kg})$ C. afer, Snail Slime, and, combined $C$. afer and snail slime extract on blood glucose level of alloxan induced Albino rats.

\begin{tabular}{|c|c|c|c|c|c|c|c|}
\hline \multirow{2}{*}{ Group } & \multirow{2}{*}{$\begin{array}{c}\text { Dose } \\
(\mathrm{mg} / \mathrm{kg})\end{array}$} & \multirow{2}{*}{$\begin{array}{c}\text { Difference in } \\
\text { Body weight (g) }\end{array}$} & \multicolumn{5}{|c|}{ Blood glucose levels (mg/dL) } \\
\hline & & & Day 0 & Day 4 & Day 7 & Day 14 & Day 21 \\
\hline $\begin{array}{l}\text { Normal } \\
\text { Control }\end{array}$ & & +0.3 & $110 \pm 8$ & $109 \pm 6$ & $111 \pm 3$ & $110 \pm 6$ & $114 \pm 7$ \\
\hline CaLE & 300 & -0.9 & $217 \pm 15$ & $187 \pm 10$ & $163 \pm 5$ & $128 \pm 4$ & $118 \pm 2$ \\
\hline SSE & 300 & -0.5 & $218 \pm 4$ & $197 \pm 8$ & $172 \pm 4$ & $148 \pm 3$ & $123 \pm 3$ \\
\hline CaLESSE & 300 & -0.9 & $204 \pm 9$ & $183 \pm 8$ & $164 \pm 3$ & $139 \pm 4$ & $120 \pm 2$ \\
\hline GC & 5 & -0.4 & $239 \pm 13$ & $190 \pm 13$ & $145 \pm 9$ & $123 \pm 5$ & $103 \pm 2$ \\
\hline
\end{tabular}

$\mathrm{S}_{\mathrm{D}}=$ standard deviation; Mean and $\mathrm{n}=$ number of the animals per group; $\quad-=$ reduction in body weight, $+=$ increase in body weight.

for the low dose of $100 \mathrm{mg} / \mathrm{kg}$ body weight of the animal on treatment with Costus afer methanol leaf extract to $125 \mathrm{mg} / \mathrm{dL}$ after 21 days oral administration. There was no observable change indicated with regards to the body weight of the animals. The change in the average body weight before the experiment and after the experiment was $0.4 \mathrm{~g}$ (that is a reduction in weight which was not significant after 21 days of oral administration of the extract).

From the investigation shown on Table 2, the effect of high dose of $300 \mathrm{mg} / \mathrm{kg}$ Costus afer methanol leaf extract on fasting blood glucose level for 21 days oral administration yielded an average significant reduction of $99 \mathrm{mg} / \mathrm{dL}$ (i.e. from $217 \mathrm{mg} / \mathrm{dL}$ to $118 \mathrm{mg} / \mathrm{dL}$ ). The body weight reduction gave an average of 0.9 $\mathrm{mg} / \mathrm{dL}$ which was not significant. However the high dose of the Costus afer methanol leaf extract on blood glucose level for 21 days oral administration shows more effect of hypoglycemia activity than the lower dose.

Similarly, Table 1 shows the effect of low dose of $100 \mathrm{mg} / \mathrm{kg}$ snail slime (SSE) on blood glucose level was investigated on five rats for 21 days oral administration, indicated a reduction in blood glucose level from day 0 to day 21 with an average reduction of $87 \mathrm{mg} / \mathrm{dL}$ associated with non-significant body weight reduction of $0.3 \mathrm{~g}$. The effect for high dose of $300 \mathrm{mg} / \mathrm{kg}$ of snail slime on blood 
glucose level after 21 days of oral administration gave an average of $95 \mathrm{mg} / \mathrm{dL}$ blood glucose reduction and a body weight reduction of $0.5 \mathrm{~g}$ as shown on Table 2.

For the combined $C$. afer and snail slime extract as shown on Table 1 and Table 2, indicated that a low dose of $100 \mathrm{mg} / \mathrm{kg}$ had an average blood glucose level reduction of $95 \mathrm{mg} / \mathrm{dL}$ and a body weight reduction of $0.4 \mathrm{~g}$ whereas the high dose of combined C. afer and snail slime extract $(300 \mathrm{mg} / \mathrm{kg})$ gave a blood glucose level and body weight reduction of $84 \mathrm{mg} / \mathrm{kg}$ and $0.9 \mathrm{~g}$ respectively.

To buttress the investigation, a $5 \mathrm{mg} / \mathrm{kg}$ standard hypoglycaemic drug (Glibenclamide) was also administered on the animals at similar conditions to compare the effect of the plant material ( $C$. afer), snail slime and the combined $C$. afer and snail slime extract on blood glucose level of the animal after 21 days oral administration. The result indicated that there was a significant reduction on blood glucose level to a tune of $136 \mathrm{mg} / \mathrm{dL}$ while the body weight of the animals was reduced to $0.4 \mathrm{~g}$.

The following plots indicated the blood glucose level effects of the extract, slime and combined $C$. afer and snail slime with the standard pharmaceutical drug (Glibenclamide, $5 \mathrm{mg} / \mathrm{kg}$ ) respectively over 21 days oral administration. In each of the presentation the normal control and the standard pharmaceutical drug was constantly used to compare the plant extract, the snail slime and the $C$. afer and snail slime extract in each case for effect of the blood glucose reduction.

From the investigation shown on Figure 3, there was an indication of reduction of the fasting blood glucose level from an average of $228 \mathrm{mg} / \mathrm{dL}$ for the low dose of $100 \mathrm{mg} / \mathrm{kg}$ body weight of the animal on treatment with $C$. afer methanol leaf extract to $125 \mathrm{mg} / \mathrm{dL}$ after 21 days oral administration. There was no observable change indicated with regards to the body weight of the animals. The change in the average body weight before the experiment and after the experiment was $0.4 \mathrm{~g}$ (that is a reduction in weight which was not significant after 21 days of oral administration of the extract).

From the investigation shown on Figure 4, the effect of high dose of 300 $\mathrm{mg} / \mathrm{kg}$ C. afer methanol leaf extract on fasting blood glucose level for 21 days oral administration yielded an average reduction of $99 \mathrm{mg} / \mathrm{dL}$ (i.e. from 217 $\mathrm{mg} / \mathrm{dL}$ to $118 \mathrm{mg} / \mathrm{dL}$ ). The body weight reduction gave an average of $0.9 \mathrm{mg} / \mathrm{dL}$ which was not significant. However the high dose of the $C$. afer methanol leaf extract on blood glucose level for 21 days oral administration shows more effect of hypoglycemic activity than the lower dose.

Similarly, as shown on Figure 5, the effect of low dose of $100 \mathrm{mg} / \mathrm{kg}$ snail slime (SSE) on blood glucose level was investigated on five rats for 21 days oral administration. There was an indication of significant reduction in blood glucose level from day 0 to day 21 with an average reduction of $87 \mathrm{mg} / \mathrm{dL}$ associated with non-significant body weight reduction of $0.3 \mathrm{~g}$.

As shown on Figure 6, the effect for high dose of $300 \mathrm{mg} / \mathrm{kg}$ of snail slime on blood glucose level after 21 days of oral administration gave an average of 95 $\mathrm{mg} / \mathrm{dL}$ blood glucose reduction and a body weight reduction of $0.5 \mathrm{~g}$. 


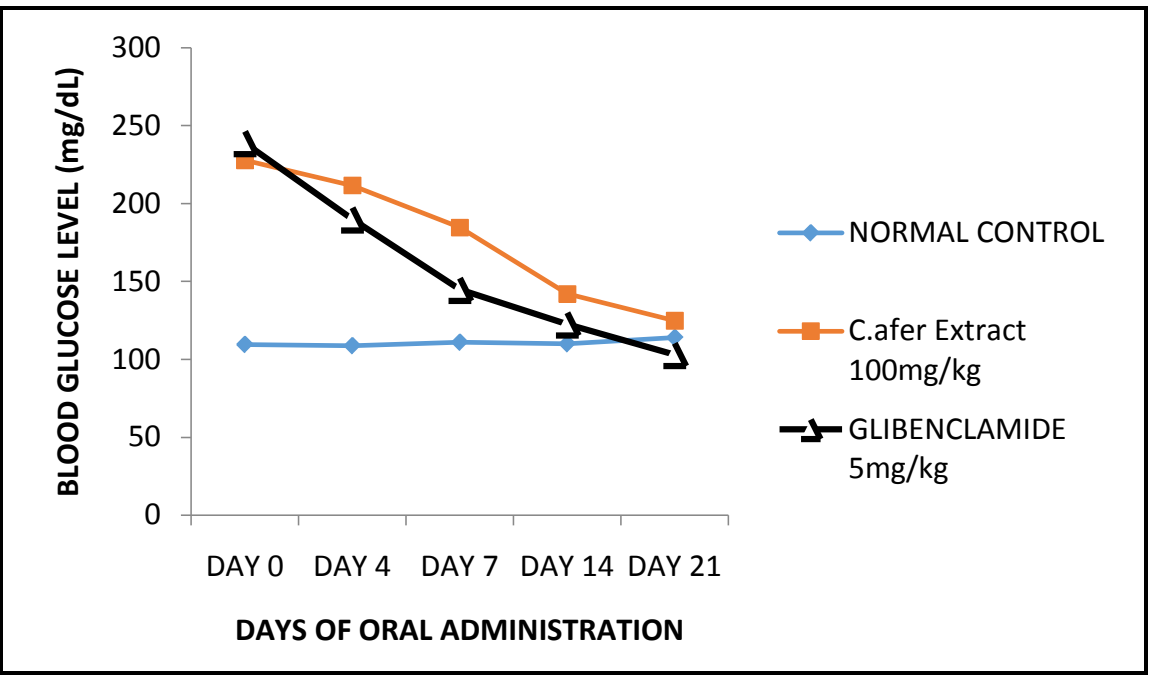

Figure 3. Effect of C. afer $(100 \mathrm{mg} / \mathrm{kg} \mathrm{bw})$ and Glibenclamide $(5 \mathrm{mg} / \mathrm{kg})$ on Swiss albino rats.

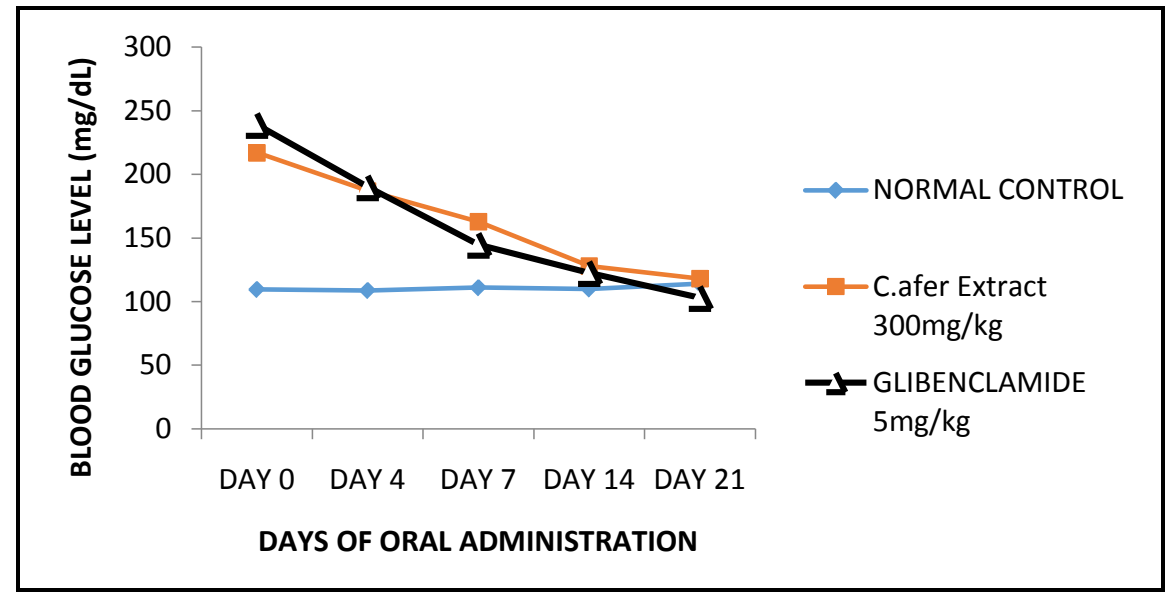

Figure 4. Effects of C. afer $(300 \mathrm{mg} / \mathrm{kg} \mathrm{bw})$ and Glibenclamide $(5 \mathrm{mg} / \mathrm{kg})$ on Swiss Albino Rats.

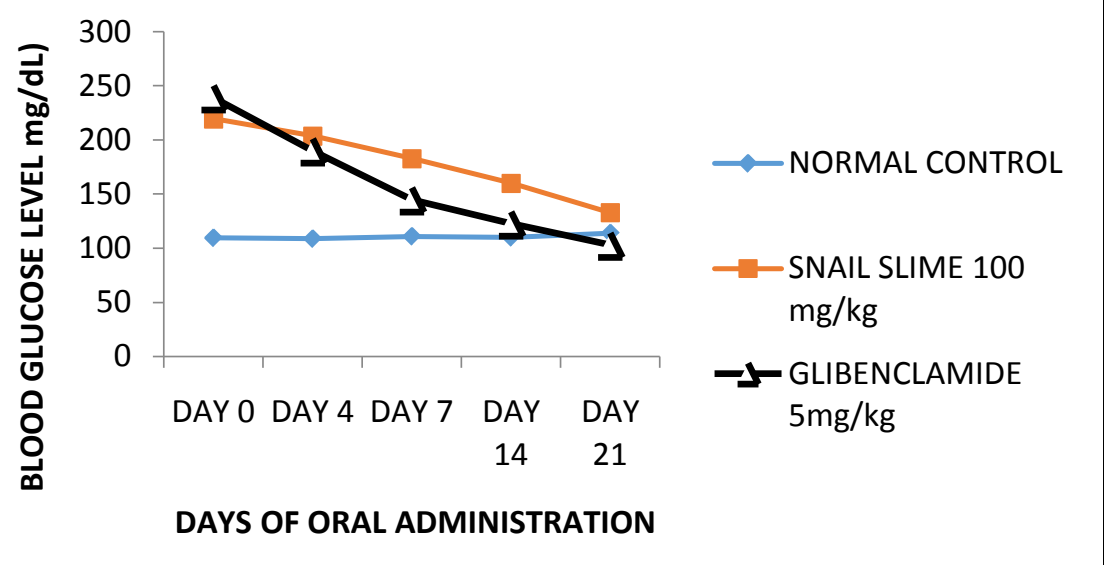

Figure 5. Effects of Snail Slime (100 mg/kg bw) and Glibenclamide $(5 \mathrm{mg} / \mathrm{kg})$ on Swiss Albino Rats. 


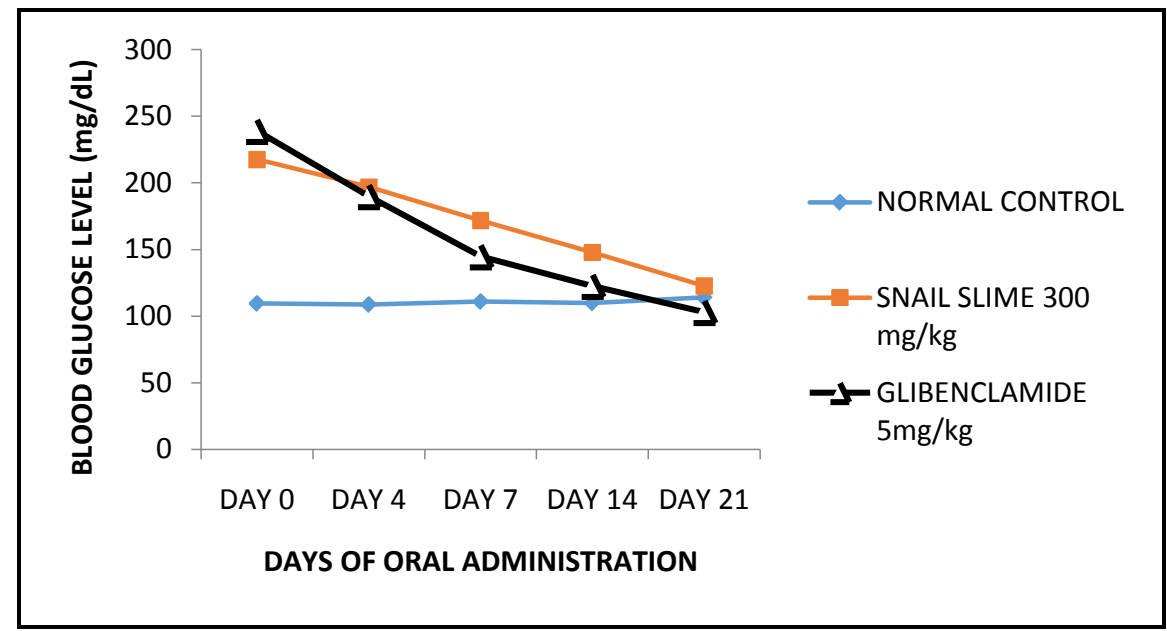

Figure 6. Effects of Snail Slime (300 mg/kg bw) and Glibenclamide (5 mg/kg) on Swiss Albino Rats.

For the combined $C$. afer methanol leaf extract, and snail slime extracts on Figure 7, it was observed that a low dose of $100 \mathrm{mg} / \mathrm{kg}$ had an average blood glucose level reduction of $95 \mathrm{mg} / \mathrm{dL}$ and a body weight reduction of $0.4 \mathrm{~g}$ whereas the high dose of combined $C$. afer methanol leaf extract and snail slime at $300 \mathrm{mg} / \mathrm{kg}$ gave a blood glucose level and body weight reduction of $84 \mathrm{mg} / \mathrm{kg}$ and $0.9 \mathrm{~g}$ respectively as shown on Figure 8.

To buttress the discussion on the investigation, a $5 \mathrm{mg} / \mathrm{kg}$ standard hypoglycaemic drug (Glibenclamide) was also used on the animals to compare the effect of the plant material (C. afer), snail slime and the combined C. afer and snail slime extracts on blood glucose level of the animal after 21 days oral administration. The result indicated that there was a reduction on both blood glucose level and body weight of the animals as $136 \mathrm{mg} / \mathrm{dL}$ and $0.4 \mathrm{~g}$ respectively. Similar result was obtained in the work of [27] where significant reduction of fasting blood glucose level was observed for doses of 100,200 , and $400 \mathrm{mg} / \mathrm{kg}$ body weight at $44.91,38.70$ and $53.63 \%$ respectively in comparison to the reduction obtained with glibenclamide $(5 \mathrm{~g})$ used as standard drug.

\section{Conclusions}

Since prehistoric time people have tried to find medications to ameliorate and cure different illnesses. At every successive century from the development of humankind with the trend of civilizations, the healing properties of many medicinal plants were identified, noted, and conveyed to our generation as detected on $C$. afer leaf and snail slime extracts in this investigation. The results of the effect of $C$. afer leaf methanol extract, snail slime and combined $C$. afer and snail slime extracts on blood glucose level revealed that at high dose of $300 \mathrm{mg} / \mathrm{kg}$ body weight of the animal there was average reduction of blood glucose level without any significant side effect as compared to the low dose of $100 \mathrm{mg} / \mathrm{kg}$ body weight of the animal for the same extracts after 21 days oral administration. 


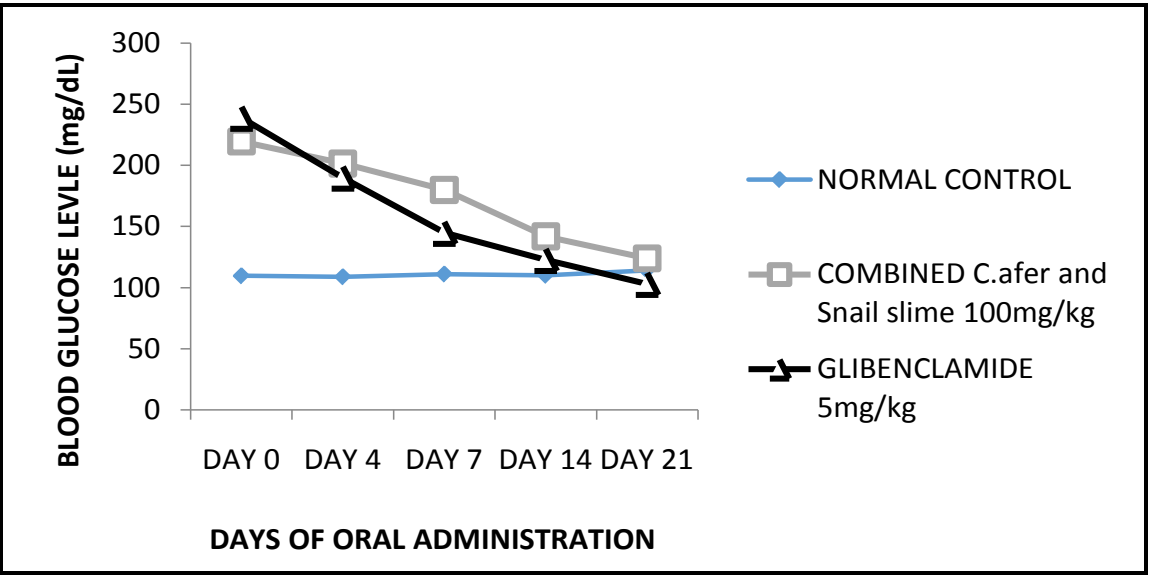

Figure 7. Effects of combined extract (CaLME/SSE) $(100 \mathrm{mg} / \mathrm{kg} \mathrm{bw})$ and Glibenclamide $(5 \mathrm{mg} / \mathrm{kg})$ on Swiss Albino Rats.

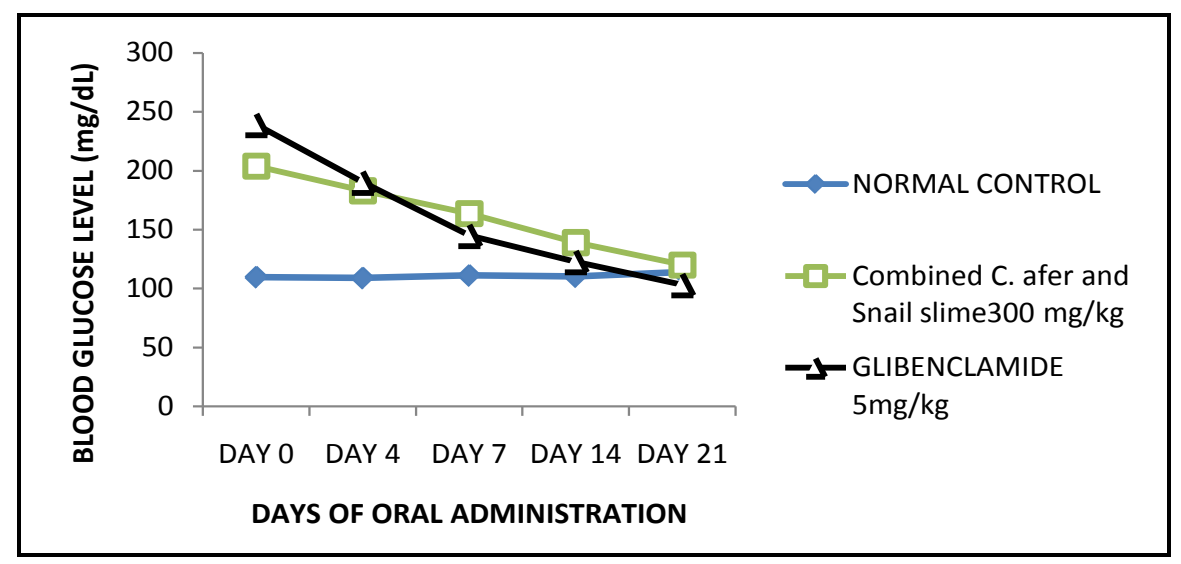

Figure 8. Effects of Combined extracts (CaLME/SSE) (300 mg/kg bw) and Glibenclamide $(5 \mathrm{mg} / \mathrm{kg})$ on Swiss Albino Rats.

The results obtained when alloxan induced rats was treated with $C$. afer leaf methanol extract, Snail slime extract, and combined $C$,afer and snail slime extracts was analysed using Statistix 8.0 American version. The results showed a dose dependent fashion and the difference obtained from the compared results was statistically significant at $\mathrm{p}<0.05$.

Conclusively, this investigation may achieve the formation of new strategies for the development of novel antidiabetic drug to treat serious condition like diabetes which represents a global public health problem. Based on the idea that snail uses its slime to regenerate its shell and skin when broken or damaged hence the regenerative capacity of snail slime and the fact that diabetes is characterized by damage of the pancreatic beta cells, may give credit to the reduction of blood glucose level observed in the use of $C$. afer methanol leaf extract and snail slime for possible for anti-diabetic treatment.

\section{Acknowledgements}

The authors of this work wish to specially thank Mr Cletus Ukwubile for his 
academic guidance and contributions throughout this work. In another vein, we wish to thank the technicians (Paul, Elisha, Caleb and Titus) of Chemistry unit of the Science Laboratory Technology, Federal Polytechnic, Bali for their technical assistance during the process of this study.

\section{References}

[1] Tanira, M.O.M. (1994) Antidiabetic Medicinal Plants: A Review of the Present Status and Future Directions. International Journal of Diabetes, 2, 15-22.

[2] Anaga, A.O., Njoku, C.J., Ekejiuba, E.S., Esiaka, M.N. and Asuzu, I.U. (2004) Investigation of the Methanolic Leaf Extract of Costus afer Ker for Pharmacological Activities in Vitro and in Vivo. Phytomedicine, 2-3, 242-248. https://doi.org/10.1078/0944-7113-00349

[3] van Wyk, B.-E., van Oudstshoorn, B. and Gerickle, N. (1997) Medicinal Plants of South Africa. Pretoria: Briza, 214-215.

[4] Barminas, J.T., Agu, M.O., Onwuka, J.C. and Ukwubile, C.A. (2017) The Physicochemical, Toxicity and Anti-Diabetic Effect of Costus afer Ker Gawl. (Costaceae) Leaf Methanol Extract and Snail Slime on Alloxan Induced White Swiss Albino Rat. AASCIT Journal of Chemistry, 3, 23-29.

[5] Kinghorn, A.D. and Balandrin, M.F. (1993) Human Medical Agents from Plants. American Chemical Society, San Francisco. https://doi.org/10.1021/bk-1993-0534

[6] Kong, J.M., Goh, N.K., Chia, L.S. and Chia, T.F. (2003) Recent Advances in Traditional Plants Drugs and Orchids. Acta Pharmacologia Scinc, 24, 7-21.

[7] Phillipson, J.D. (2001) Phytochemistry and Medicinal Plants. Phytotherapy, 56, 237-243. https://doi.org/10.1016/S0031-9422(00)00456-8

[8] Okigbo, R.N. and Mmeka, E.C. (2006) An Appraisal of Phytomedicine in Africa. KMITL Science and Technology Journal, 6.

[9] Sofowora, A. (1993) Medicinal Plants and Traditional Medicine in Africa. 2nd Edition Spectrum Books, Ibadan, 26-100.

[10] Ukpabi, C.F., Agbafor, K.N., Ndukwe, O.K., Agwu, A. and Nwachukwu, S.N. (2012) Phytochemical Composition of Costus afer Extract Its Alleviation of Carbon Tetrachloride Induced Hepatic Oxidative Stress and Toxicity. International Journal of Modern Botany, 2, 120-126.

[11] Gurib-Fakim, A. (2006) Medicinal Plants; Traditions of Yesterday and Drugs of Tomorrow. Molecular Aspects of Medicine, 27, 1-93.

https://doi.org/10.1016/j.mam.2005.07.008

[12] Griggs, B. (1981) Green Pharmacy, a History of Herbal Medicine. J. Norman \& Hobhouse Ltd., London.

[13] Heinrich, M., Barnes, J., Gibbons, S. and Williamson, E.M. (2004) Fundamentals of Pharmacognosy and Phytotherapy. Churchill Livingstone, Elsevier Science Ltd., UK.

[14] Goldman, P. (2001) Herbal Medicines Today and the Roots of Modern Pharmacology. Annals of Internal Medicine, 135, 594-600.

https://doi.org/10.7326/0003-4819-135-8_Part_1-200110160-00010

[15] Gupta, R., Gabrielsen, B. and Ferguson, F.M. (2005) Nature's Medicines; Traditional Knowledge and Intellectual Property Management. Case Studies from the National Institutes of Health (NIH). USA Current Drug Discovery Technologies, 2, 203-219. https://doi.org/10.2174/157016305775202937 
[16] Newman, D.J., Cragg, G.M. and Snader, K.M. (2003) Natural Products as Sources of New Drugs over the Period 1981-2002. Journal of Natural Products, 66, 1022-1032. https://doi.org/10.1021/np0300961

[17] WHO (2001) Legal Status of Traditional Medicines and Complementary Alternative Medicine: A Worldwide Review. WHO Publishing, 1.

[18] Fransworth, N.R. (1994) Ethnopharmacology and Drug Development. In: Chadwick, D.J. and Marsh, J., Eds., Ethnobotany and the Search for New Drugs, CIBA Foundation Symposium 185, John Wiley and Sons, Chichester, New York, 42-51.

[19] Zhang, B.B. and Moller, D.E. (2000) New Approaches in the Treatment of Type 2 Diabetes. Current Opinion in Chemical Biology, 4, 461-467. https://doi.org/10.1016/S1367-5931(00)00103-4

[20] Tapsell, L.C. (2006) Health Benefits of Herbs and Spices: The Past, the Present, the Future. Medical Journal of Australia, 1, 4-24.

[21] Adikwu, M.U. and Nnamani, P.O. (2005) Some Physiological and Toxicological Properties of Snail Mucin. Bioresearch, 5, 1-6.

[22] Asit, R.S. and Sunil, B.B. (2015) Formulation and Evaluation of Phytosome Drug Delivery System of Boswellia Serrate Extract. International Journal of Research in Medicine, 4, 94-99.

[23] Raghavan, B. and Krishna, K.S. (2006) Effect of Terminalia arjuna Stem Bark on Anti-Oxidant Status in Liver and Kidney of Alloxan Diabetic Rats. Indian Journal of Physiology and Pharmacology, 50, 133-142.

[24] Vijayavargia, R., Kumar, M. and Gupta, S. (2000) Hypoglycaemic Effect of Aqueous Extract of Enicostemma littorale Blume (Chhotachirayata) on Alloxan Induced Diabetes Milletus in Rats. Indian Journal of Experimental Biology, 38, 781-784.

[25] Dimo, T., Rakotonirina, S.V., Tan, P.V., Azay, J. and Dongo, E. (2007) Effect of Sclerocarya birrea (Anacardiaceae) Stem-Bark Methylene Chloride/Methanol Extract on Streptozotocin Diabetic Rats. Journal of Ethnopharmacology, 110, 434-438.

[26] Ukwubile Cletus, A., Agu Matthew, O. and Elsie Joseph, A. (2015) Phytochemical Screening and Acute Toxicity Studies of Melastomastrum capitatum (Vahl) A. Fern and R. Fern (Melastomataceae) Leaf Methanol Extract. American Journal of Biological Chemistry, 3, 57-62.

[27] Moke, E.G., Ilodigwe, E.E., Okonta, J.M., Emudainohwo, J.O.T., Ajaghaku, D.L., Erhirhie, O.E., Chinwuba, P. and Ahanta, E. (2015) Antidiabetic Activity and Toxicity Evaluation of Aqueous Extract of Spondias mombin and Costus afer on Wistar Rats. British Journal of Pharmaceutical Research, 6, 333-345. 